\title{
Modulation of Fear Memory by Dietary Polyunsaturated Fatty Acids via Cannabinoid Receptors
}

\author{
Daisuke Yamada ${ }^{1,2}$, Jiro Takeo ${ }^{3}$, Peter Koppensteiner ${ }^{1,2,4}$, Keiji Wada ${ }^{1,2}$ and Masayuki Sekiguchi*,1,2 \\ 'Department of Degenerative Neurological Diseases, National Institute of Neuroscience, National Center of Neurology and Psychiatry, Kodaira, \\ Tokyo, Japan; ${ }^{2}$ CREST, Japan Science and Technology Agency, Kawaguchi, Saitama, Japan; ${ }^{3}$ Central Research Laboratory, Tokyo Innovation \\ Center, Nippon Suisan Kaisha, Hachioji, Tokyo, Japan; ${ }^{4}$ Medical University of Vienna, Vienna, Austria
}

\begin{abstract}
Although the underlying mechanism remains unknown, several studies have suggested benefits of n-3 long-chain polyunsaturated fatty acid (PUFA) for patients with anxiety disorders. Elevated fear is thought to contribute to the pathogenesis of particular anxiety disorders. The aim of the present study was to evaluate whether the dietary n-3 to n-6 PUFA (3:6) ratio influences fear memory. For this purpose, the effects of various dietary 3:6 ratios on fear memory were examined in mice using contextual fear conditioning, and the effects of these diets on central synaptic transmission were examined to elucidate the mechanism of action of PUFA. We found that fear memory correlated negatively with dietary, serum, and brain 3:6 ratios in mice. The low fear memory in mice fed a high 3:6 ratio diet was

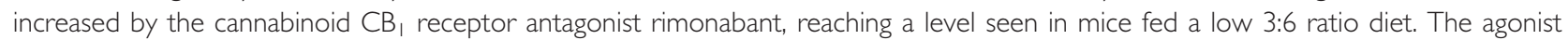
sensitivity of $C B$, receptor was enhanced in the basolateral nucleus of the amygdala (BLA) of mice fed a high 3:6 ratio diet, compared with that of mice fed a low 3:6 ratio diet. Similar enhancement was induced by pharmacological expulsion of cholesterol in the neuronal membrane of brain slices from mice fed a low 3:6 ratio diet. $C B$, receptor-mediated short-term synaptic plasticity was facilitated in pyramidal neurons of the BLA in mice fed a high 3:6 ratio diet. These results suggest that the ratio of $n-3$ to $n-6$ PUFA is a factor regulating fear memory via cannabinoid $\mathrm{CB}_{1}$ receptors.

Neuropsychopharmacology (2014) 39, I852-1860; doi:I0.1038/npp.20I4.32; published online I2 March 20I4
\end{abstract}

Keywords: polyunsaturated fatty acid; fear memory; cannabinoid; amygdala; nutrition; anxiety disorder

\section{INTRODUCTION}

Long-chain polyunsaturated fatty acids (PUFAs) are a major nutrient essential for human health (Horrocks and Farooqui, 2004). In the mammalian brain, there are two major classes of PUFA, n-3 and n-6. Mammals cannot convert PUFAs from one family into those from the other; n-3 and n-6 PUFAs are directly ingested or biosynthesized from their precursor PUFAs. The fatty acid composition of the brain can be extensively modulated by dietary lipids (Youdim et al, 2000). PUFAs are major components of the plasma membrane, where they influence membrane fluidity (Salem and Niebylski, 1995; Yang et al, 2011). Lifelong insufficiency of n-3 PUFAs induces changes in rodent behaviors (Lafourcade et al, 2011; Larrieu et al, 2012; Takeuchi et al, 2003) and cannabinoid signaling in the brain (Lafourcade et al, 2011; Larrieu et al, 2012). However, the

*Correspondence: Dr M Sekiguchi, Department of Degenerative Neurological Diseases, National Institute of Neuroscience, National Center of Neurology and Psychiatry, 4-I-I Ogawahigashi, Kodaira, Tokyo |87-8502, Japan, Tel: +8| 4234 | 27| I, Fax: +8| 42346 I745, E-mail: elecl@ncnp.go.jp or sekiguch@ncnp.go.jp

Received 31 July 2013; revised 3 February 2014; accepted 6 February 2014; accepted article preview online 12 February 2014 effect of n-3 PUFA supplementation on brain function in rodents not deficient in $n-3$ is not yet known.

We conducted a literature search for studies examining PUFA involvement in anxiety disorders, excluding depression, which yielded four results. Supplementation with n-3 PUFA, docosahexaenoic acid (22:6n-3; DHA), and another n-3 PUFA, eicosapentaenoic acid (20:5n-3; EPA), after a traumatic experience prevented the development of posttraumatic stress disorder (PTSD) (Matsuoka et al, 2010). Similar supplementation given to female members of rescue groups in a severe disaster reportedly reduced the incidence of PTSD (Nishi et al, 2012). Furthermore, DHA, EPA, and the n-3 PUFA $\alpha$-linolenic acid (18:3n-3) are significantly decreased (by $18 \%, 36 \%$, and $32 \%$, respectively) in red blood cell membranes of patients with social anxiety disorder compared with controls (Green et al, 2006); in the same study, the ratio of n-6 to n-3 PUFA differed significantly between patients and controls. An association between dietary intake of DHA and clinically determined anxiety disorders was demonstrated in a cross-sectional, communitybased study in women (Jacka et al, 2013). The biological mechanism underlying the contribution of the ratio of $n-3$ to n-6 PUFA (3:6) in anxiety disorders is unknown.

It is widely accepted that fear memory and its abnormal processing are involved in the pathogenesis of anxiety 
disorders in which fear is a contributory factor (Cuthbert et al, 2003). For example, PTSD develops following exposure to a life-threatening event, and the persistence of traumatic memories in PTSD is often explained in terms of a traumainduced enhancement of fear memory encoding (Debiec and LeDoux, 2006; O'Donnell et al, 2004). It is also known that PTSD involves an impairment of fear extinction (Milad et al, 2006; Rauch et al, 2006).

Fear conditioning is an experimental model for conditioned fear memory (LeDoux, 2000), which is essential for an individual's survival. Many studies suggest that this pivotal memory is influenced by manipulation of cannabinoid signaling that, in the brain, represses neurotransmitter release through cannabinoid $\mathrm{CB}_{1}$ receptors. For example, extinction of auditory fear memory is impaired in $\mathrm{CB}_{1}$ receptor knockout mice without any changes in memory acquisition or consolidation (Marsicano et al, 2002). Furthermore, the $\mathrm{CB}_{1}$ receptor neutral antagonist, $\mathrm{AM} 4113$, exerts no effect on the expression of contextual fear memory in rats (Sink et al, 2010). On the other hand, systemic administration of the $\mathrm{CB}_{1}$ agonists WIN55,212-2 (WIN) or HU-210 impairs contextual fear conditioning in rats (Mackowiak et al, 2009; Pamplona and Takahashi, 2006). In addition, pre-test microinjection of another $\mathrm{CB}_{1}$ agonist, anandamide, into the dorsolateral periaqueductal gray (PAG) or ventromedial prefrontal cortex (vmPFC) impairs contextual fear conditioning in rats (Lisboa et al, 2010; Resstel et al, 2008). These results consistently suggest that activation of $\mathrm{CB}_{1}$ receptors reduces contextual fear memory.

The aim of the present study was to evaluate whether dietary 3:6 ratio influences fear memory in mice not deficient in $\mathrm{n}-3$, and, if so, to identify the underlying mechanism(s). Such information would be valuable for the clinical utilization of PUFAs. For this purpose, we examined the effects of various dietary 3:6 ratios on mouse fear memory in contextual fear conditioning experiments.

\section{MATERIALS AND METHODS}

\section{Animals and Feeding of Diets}

Male C57BL/6J mice were purchased at 4-5 weeks of age and fed a solid standard mouse diet CE-2 (Clea, Tokyo, Japan; see Supplementary Table S2) for 1 week. The mice subsequently received chow containing various amounts of n-3 and n-6 PUFAs for 6 weeks (see Results for dietary PUFA analysis). The mice were housed four or five per cage under controlled temperature $\left(25 \pm 1{ }^{\circ} \mathrm{C}\right)$ and lighting (12 $\mathrm{h}$ light-dark cycle) conditions, and water was provided ad libitum. Animal procedures were in strict accordance with the guidelines of the National Institute of Neuroscience, National Center of Neurology and Psychiatry (Tokyo, Japan) and were approved by the Institutional Animal Investigation Committee.

\section{Contextual Fear Conditioning}

Immediately after the 6-week feeding period, a contextual fear conditioning test and extinction session were conducted as described previously (Yamada et al, 2009). The freezing response is expressed as the percentage of time that the mouse spent freezing during a $180 \mathrm{~s}$ time window. See Supplementary Methods for detailed descriptions.

\section{Other Behavioral Tests}

The open-field, shock-sensitivity, and light-dark transition tests were performed as described previously (Sakurai et al, 2008). The procedure for the Y-maze test was based on a previous report (Sarter et al, 1988).

\section{Analysis of Fatty Acids}

The fatty acid content of the diets and the mouse serum and brain were determined using gas chromatography (Lepage and Roy, 1986). See Supplementary Methods for detailed descriptions.

\section{Quantitative Real-Time PCR}

See Supplementary Methods.

\section{Electrophysiology}

Whole-cell patch-clamp recordings from pyramidal neurons in the basolateral nucleus of the amygdala (BLA) were performed as described previously (Yamada et al, 2012; Zushida et al, 2007). See Supplementary Methods for detailed descriptions.

\section{Drugs}

Rimonabant (RIM; SR141716A) was purchased from Cayman Chemicals (Ann Arbor, MI). Naloxone (NLX), WIN, and methyl- $\beta$-cyclodextrin (MCD) were purchased from Sigma (St Louis, MO). For subcutaneous administration, RIM was dissolved in vehicle (VEH) containing 2.5\% dimethyl sulfoxide (DMSO) and 1.0\% Tween-80 in saline solution. NLX was dissolved in saline. For electrophysiological experiments, RIM and WIN were dissolved in DMSO at 5 and $10 \mathrm{mM}$, respectively, and diluted in artificial cerebrospinal fluid (aCSF) at final concentrations as indicated in Results and Figure legends.

\section{Statistical Analysis}

All data are shown as mean \pm SEM. The data were analyzed by one- or two-way analysis of variance (ANOVA) for comparisons among three or more groups. If the ANOVA results were significant, post hoc Bonferroni multiple comparisons were performed. The two-tailed unpaired $t$-test was used for statistical comparisons between two groups. Spearman's rank correlation coefficient $(\rho)$ was calculated for correlation analyses. $P<0.05$ was considered statistically significant.

\section{RESULTS}

We prepared eight varieties of chow (Supplementary Table S1). Mice (5-6 weeks of age at the start of the experiment) were fed one variety for 6 weeks. Behavioral, biochemical, and electrophysiological experiments followed. The control 1 diet was similar to the n-3 non-deficient standard AIN-93 diet (Reeves et al, 1993), with soybean oil as the fat 
component (Supplementary Table S1). The test diets were prepared by replacing soybean oil with oils rich in n-3 PUFAs $(2.5 \%$ krill oil, 5\% krill oil, 5\% krill oil + linoleic acid (18:2n-6, LA; n-6 PUFA), 2.5\% fish oil, 5\% fish oil, $2.5 \%$ fish oil + olive oil (OL)). Krill oil was prepared from Antarctic krill and fish oil was prepared from sardines. The oils were mixed with the other chow components before solidification. Total fat contents did not differ among the diets that were compared. The fatty acid compositions and the 3:6 ratios of all diets are listed in Supplementary Table S2.

\section{Dietary, Brain, and Serum Ratios of n-3 to n-6 PUFAs Influence Contextual Fear Memory}

Figure 1a shows the fraction of time that mice $(n=12$ for all groups) spent freezing during a 3-min behavioral test session (re-exposure of mice to a conditioning box $24 \mathrm{~h}$ after contextual fear conditioning). The freezing rate was highest in mice fed the control 1 diet $(3: 6=0.14 ; n-3$ PUFA content, 0.44\%; Figure 1a), lower in those fed the $2.5 \%$ krill diet $(3: 6=0.33 ; n-3$ PUFA content, $0.89 \%)$, and significantly lower (compared with the control 1 diet group) in those fed the $5 \%$ krill diet $(3: 6=0.97 ; n-3$ PUFA content, $1.32 \% ; \mathrm{F}(2,33)=8.58, \quad P=0.001$ by ANOVA, $P<0.001$ with post hoc Bonferroni comparison). Figure $1 \mathrm{~b}$ shows the time course of the freezing rate in Figure 1a. On the other hand, when the test was conducted $1 \mathrm{~h}$ after the conditioning (short-term memory test), freezing rates were almost identical in mice fed control 1 and $5 \%$ krill diets (Figures $1 \mathrm{a}$ and $\mathrm{b}$ (inset)). These results suggest that mice fed diets with a higher 3:6-ratio or n-3 PUFA content showed reduction of long-term contextual fear memory.


e
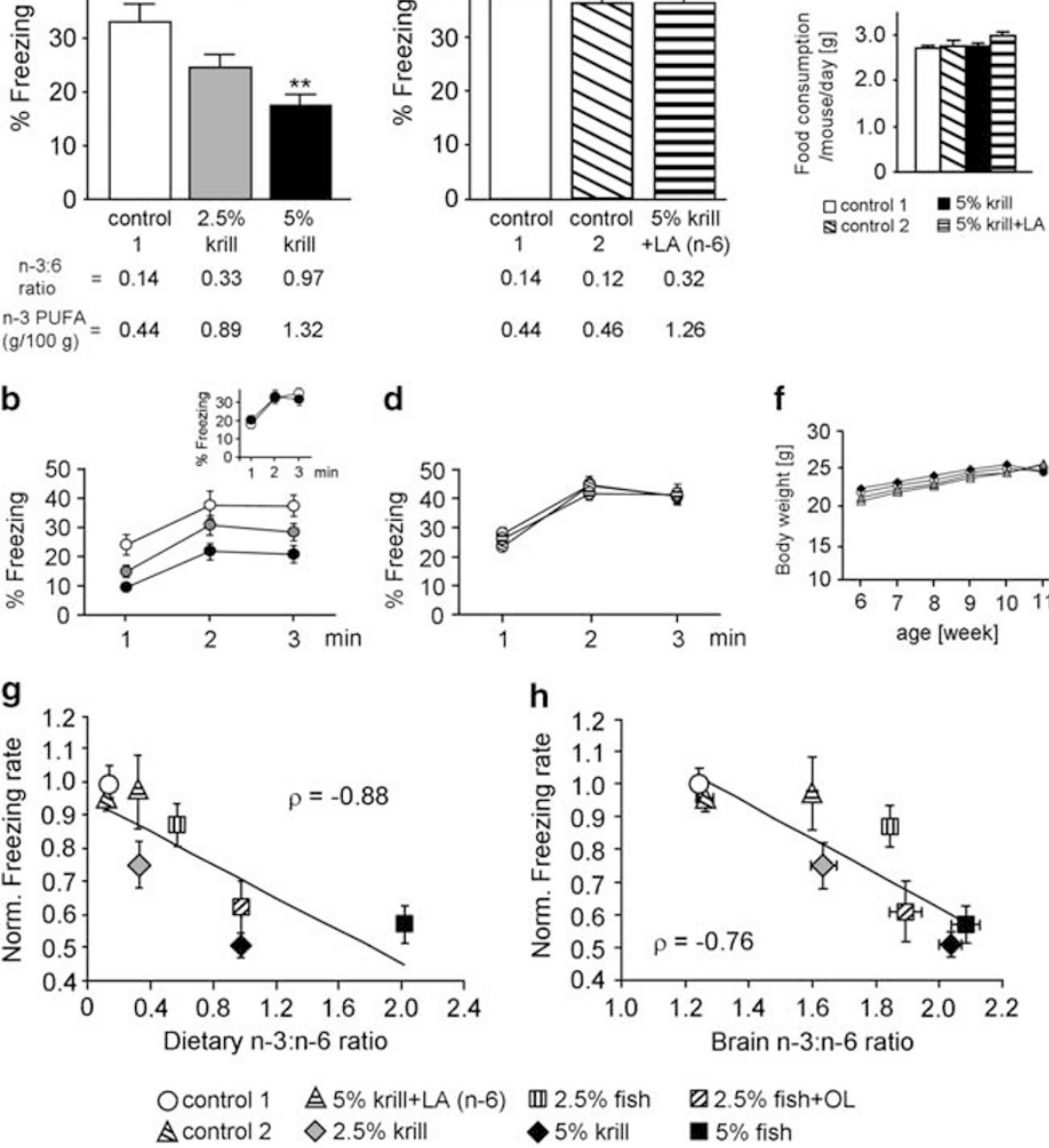

Figure I Dietary ratio of n-3 to n-6 polyunsaturated fatty acids (PUFAs) influences contextual fear memory. (a) Dose-dependent reduction of contextual fear memory ( $24 \mathrm{~h}$ after conditioning) induced by krill diets ( $n=12$ per group). (a, inset) Short-term memory test, conducted I h after conditioning ( $n=10$ per group). (b) Time course of the freezing rate during the test session in (a). (b, inset) Time course of the freezing rate during test session in (a, inset) ( $n=10$ per group). (c) Increasing the content of linoleic acid (LA) abolished the fear-attenuating effect of the $5 \%$ krill diet (control I, $n=7$; control 2, $n=10 ; 5 \%$ krill $+L A, n=10)$. Control 2 diet was used to compensate for the higher total fat content ( $9.5 \%)$ after addition of LA to the $5 \%$ krill diet (see Supplementary Table SI). (d) Time course of the freezing rate during test session in (c). (e) Food consumption measured during the I I th week in mice fed the control I $(n=12)$, control $2(n=10), 5 \%$ krill $(n=12)$, and 5\% krill $+L A(n=10)$ diets. ( $f$ Body weight changes in mice fed the control I $(n=12)$, control $2(n=10), 5 \%$ krill $(n=12)$, and 5\% krill $+L A(n=10)$ diets. ( $g$ and h) Correlation between dietary $(\mathrm{g})$ or brain (h) 3:6 ratio and freezing rate. $\rho$, Spearman's rank correlation coefficient. All data are shown as means \pm SEM. ${ }^{*} * P<0.0$ l, one-way analysis of variance (ANOVA) and post hoc Bonferroni comparison. 
To determine the factor(s) governing fear memory, mice were fed the 5\% krill diet with added LA to change the dietary 3:6-ratio (3:6 $=0.32$; n-3 PUFA content, $1.26 \%$; see also Supplementary Tables S1 and S2). LA is an n-6 PUFA and a precursor of arachidonic acid (20:4n-6, AA; n- 6 PUFA). Because total fat content was increased to $9.5 \%$ by adding LA, we prepared a new control diet, control 2, to compensate for the higher total fat content $(3: 6=0.12 ; n-3$ PUFA content, $0.46 \%$; see also Supplementary Tables $\mathrm{S} 1$ and S2). The freezing rate in mice fed this $5 \%$ krill + LA diet $(n=10)$ was almost identical to that in mice fed the control 2 diet $(n=10$; Figure 1c). Time course of the freezing rate is shown in Figure 1d. We also confirmed that freezing rates did not differ between the control $1(n=7)$ and control 2 diet-fed mice (Figure 1c). These results indicate that the dietary 3:6 ratio is an important factor in determining fear response: fear memory in mice is poorer if the dietary 3:6 ratio is high. In addition, the behavioral results after the $5 \%$ krill + LA diet also confirmed that the effect of the $5 \%$ krill diet on fear memory was not due to trace impurities in the krill oil, because the content of krill oil was the same in the $5 \%$ krill and 5\% krill + LA diets. To verify this, we measured food consumption ( $n=10-12$; Figure 1e) and body weight $(n=10-12$; Figure 1f). No significant changes were observed in daily dietary consumption among mice fed the control 1, control 2, 5\% krill, and 5\% krill + LA diets (Figure 1e). Similarly, there were no major differences in body weight gain from the start of feeding (postnatal week 6) until the end of feeding (postnatal week 11) (Figure 1f).

These results are summarized in Figure 1g, together with the results obtained with fish oil-containing diets, plotting dietary 3:6 ratios $v s$ freezing rates normalized by the rate obtained with the control 1 diet ( $n=6$ for each diet). The plot reveals a negative correlation $(\rho=-0.88, P=0.007)$, suggesting that the dietary 3:6 ratio and contextual fear memory in mice are inversely correlated. Namely, mice fed a $5 \%$ fish oil diet $(3: 6=2.02)$ showed low freezing rates and those fed a $2.5 \%$ fish oil diet $(3: 6=0.57)$ showed high freezing rates (Figure 1g). Furthermore, we prepared a $2.5 \%$ fish oil diet in which the 3:6 ratio was increased to 0.97 by replacing soybean oil with OL. n-6 PUFA is abundant in soybean oil (Supplementary Table S2) but not in OL (in which oleic acid, 18:1n-9, is abundant). Thus, this substitution reduces the content of $n-6$ PUFA, thereby increasing the 3:6 ratio. Mice fed the $2.5 \%$ fish oil + OL diet showed lower freezing rates than those fed the equivalent diet without OL, indicating that the effects of the 3:6 ratio do not depend on the dietary n-3 source (fish or krill).

We quantified the fatty acid contents of the brain and serum (see Table 1 for brain and Supplementary Table S3 for serum) and examined the relationship between 3:6 ratio and freezing rate ( $n=6$ for each quantification). The brain sample analyzed was composed of the remaining tissue after removal of the basal ganglia and hippocampus from the

Table I Composition of Fatty Acids in the Brain (Remaining Tissue after Removal of Basal Ganglia and Hippocampus from the Cerebrum)

\begin{tabular}{|c|c|c|c|c|c|c|c|c|}
\hline Numerical symbol & Control I & $2.5 \%$ Krill & $5 \%$ Krill & Control 2 & $5 \%$ Krill + LA & $2.5 \%$ Fish & 5\% Fish & $2.5 \%$ Fish + OL \\
\hline Total SFA & $41.74 \pm 0.25$ & $41.94 \pm 0.13$ & $41.69 \pm 0.21$ & $41.57 \pm 0.16$ & $41.98 \pm 0.15$ & $41.80 \pm 0.14$ & $41.62 \pm 0.43$ & $42.00 \pm 0.15$ \\
\hline Total MUFA & $18.07 \pm 0.05$ & $17.32 \pm 0.10$ & $19.00 \pm 0.18$ & $17.82 \pm 0.08$ & $18.04 \pm 0.05$ & $19.41 \pm 0.06$ & $19.02 \pm 0.26$ & $19.29 \pm 0.31$ \\
\hline Total n-3 PUFA & $17.23 \pm 0.20$ & $19.45 \pm 0.13$ & $20.05 \pm 0.21$ & $17.29 \pm 0.34$ & $\mid 8.97 \pm 0.21$ & $19.58 \pm 0.16$ & $20.09 \pm 0.30$ & $19.58 \pm 0.26$ \\
\hline $18: 3 n-3$ & - & - & - & $0.01 \pm 0.01$ & - & - & - & - \\
\hline $22: 5 n-3$ & $0.08 \pm 0.04$ & $0.39 \pm 0.02$ & $0.57 \pm 0.01$ & $0.16 \pm 0.01$ & $0.42 \pm 0.01$ & $0.46 \pm 0.00$ & $0.63 \pm 0.02$ & $0.50 \pm 0.01$ \\
\hline $22: 6 n-3$ & $17.15 \pm 0.16$ & $18.90 \pm 0.10$ & $|8.94 \pm 0.1|$ & $16.55 \pm 0.07$ & $18.18 \pm 0.07$ & $18.85 \pm 0.14$ & $18.96 \pm 0.26$ & $18.75 \pm 0.24$ \\
\hline Total n-6 PUFA & $12.98 \pm 0.20$ & $|1.92 \pm 0.3|$ & $9.82 \pm 0.16$ & $|3.7| \pm 0.09$ & $11.87 \pm 0.16$ & $10.62 \pm 0.09$ & $9.69 \pm 0.26$ & $10.35 \pm 0.26$ \\
\hline $18: 2 n-6$ & $0.75 \pm 0.01$ & $0.52 \pm 0.01$ & $0.49 \pm 0.02$ & $0.77 \pm 0.0$ & $0.77 \pm 0.03$ & $0.69 \pm 0.02$ & $0.37 \pm 0.02$ & $0.46 \pm 0.02$ \\
\hline $20: 4 n-6$ & $9.61 \pm 0.10$ & $8.86 \pm 0.10$ & $7.40 \pm 0.08$ & $10.02 \pm 0.04$ & $8.67 \pm 0.06$ & $7.96 \pm 0.04$ & $7.55 \pm 0.12$ & $7.87 \pm 0.16$ \\
\hline $22: 2 n-6$ & $0.02 \pm 0.02$ & - & - & $0.07 \pm 0.02$ & - & - & $0.03 \pm 0.02$ & - \\
\hline $22: 4 n-6$ & $2.10 \pm 0.03$ & $1.74 \pm 0.06$ & $1.34 \pm 0.02$ & $2.28 \pm 0.01$ & $1.71 \pm 0.02$ & $1.44 \pm 0.02$ & $1.26 \pm 0.03$ & $1.46 \pm 0.04$ \\
\hline Unknown & $9.98 \pm 0.09$ & $9.37 \pm 0.10$ & $9.44 \pm 0.14$ & $9.61 \pm 0.07$ & $9.14 \pm 0.08$ & $8.59 \pm 0.10$ & $9.58 \pm 0.73$ & $8.78 \pm 0.52$ \\
\hline$n-3: n-6$ & $1.33 \pm 0.02$ & $1.63 \pm 0.04$ & $2.04 \pm 0.03$ & $1.26 \pm 0.03$ & $1.60 \pm 0.02$ & $1.84 \pm 0.02$ & $2.07 \pm 0.05$ & $1.89 \pm 0.05$ \\
\hline
\end{tabular}

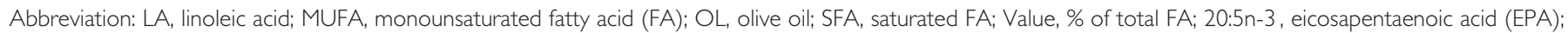
22:6n-3, docosahexaenoic acid (DHA); 18:2n-6, LA; 20:4n-6, arachidonic acid (AA); - , not detected.

Bold numerals represent significant difference $(P<0.05)$ between mice fed control $\mathrm{I}$ and $5 \%$ krill diets. 
cerebrum (mainly consisting of the cortex and amygdala). Brain and serum 3:6 ratios both correlated negatively with the freezing rate (Figures $1 \mathrm{~h}, \rho=-0.76, P=0.037$ for brain; Supplementary Figure S1, $\rho=-0.86, P=0.011$ for serum).

Taken together, these results suggest that ingestion of diets high in n-3 and low in n-6 PUFAs enhances brain and serum 3:6 ratios and attenuates contextual fear memory in mice.

\section{Extinction of Contextual Fear Memory and Other Behavioral Tests}

We tested the effects of a $5 \%$ krill diet on extinction of contextual fear memory and other behaviors, and found that no significant changes were evident in extinction $(n=8$ for each diet; Figures 2a-d), the open-field test (locomotor activity and percent center time; $n=12$ for each diet; Figure 2e), the shock-sensitivity test $(n=8$ for each diet; Figure 2f), the light-dark transition test (anxiety; $n=8$ for each diet; Figure 2g), or the Y-maze test (working memory; $n=10$ for each diet; Figure $2 \mathrm{~h}$ ). Therefore, it seems that changes in the 3:6 ratio do not alter contextual fear extinction or global behavior.

\section{Involvement of Cannabinoid $\mathrm{CB}_{1}$ Receptors}

Next, we sought to elucidate the underlying mechanism by which n-3 PUFA supplementation influences brain function. PUFAs are directly incorporated into the plasma membrane as a constituent of phospholipids (Salem and Niebylski, 1995; Youdim et al, 2000). Numerous biophysiological studies investigating n-3 PUFA incorporation into membranes have shown that (i) uptake of DHA into phospholipids results in exclusion of cholesterol from raft domains in the reconstituted membrane (Stillwell and Wassall, 2003; Stillwell et al, 2005), and (ii) reduction of cholesterol from the membrane enhances the activities of cannabinoid $\mathrm{CB}_{1}$ receptors (Bari et al, 2005a; Maccarone et al, 2009; Oddi et al, 2011). Thus, we hypothesized that endocannabinoid signaling would participate in 3:6 ratio-dependent changes in fear memory. To test this hypothesis, we subcutaneously administered RIM $(3 \mathrm{mg} / \mathrm{kg})$, a blocker of $\mathrm{CB}_{1}$ receptors (Rinaldi-Carmona et al, 1994), to mice $60 \mathrm{~min}$ before the exposure test in fear conditioning. RIM abolished the fearattenuating effect of the $5 \%$ krill diet, as revealed by comparison of the $5 \%$ krill + VEH and 5\% krill + RIM groups $(\mathrm{F}(1,36)=3.45, P<0.05$ for diet, $\mathrm{F}(1,36)=6.95, P<0.05$ for drug, and $\mathrm{F}(1,36)=12.14, P<0.01$ for interaction with twoway ANOVA; $P<0.01$ with post hoc Bonferroni comparison; $n=10$ for all four groups; Figure $3 \mathrm{a}$ ). The time course of the freezing rate is shown in Figure $3 \mathrm{~b}$. The effect of RIM on fear memory was seen only in mice fed the $5 \%$ krill diet, whereas there was no difference between the freezing rates of VEH- and RIM-injected mice fed the control 1 diet. This suggests that an elevated 3:6 ratio upregulates the endocannabinoid system.

RIM, however, is thought to have multiple sites of action in the central nervous system (CNS). In particular, a recent report demonstrated that RIM also acts on $\mu$-opioid receptors at a concentration comparable to that effective at the $\mathrm{CB}_{1}$ receptor (Zádor et al, 2012). To determine whether the $\mu$-opioid receptor is involved in the fear-
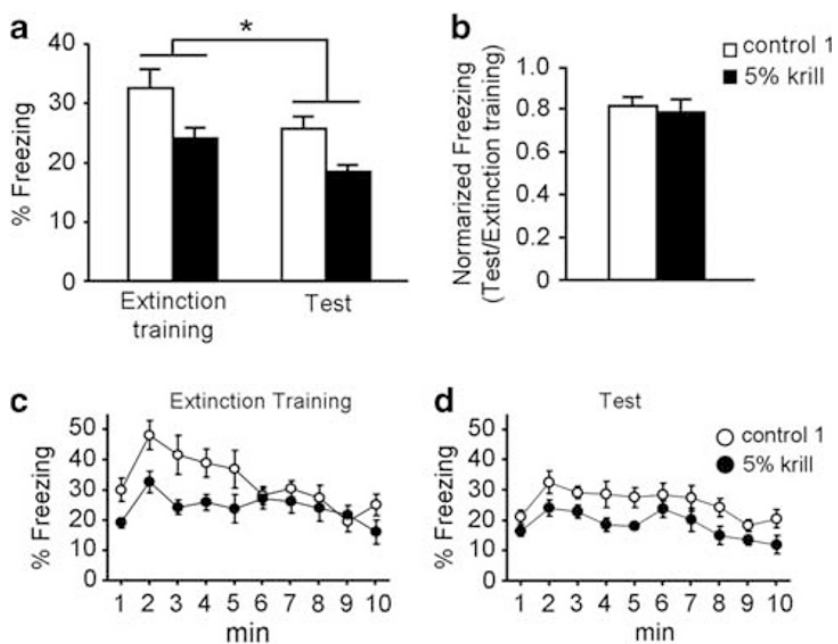

e

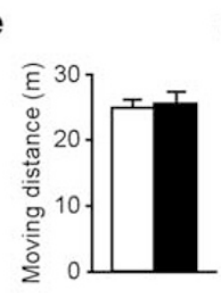

open field
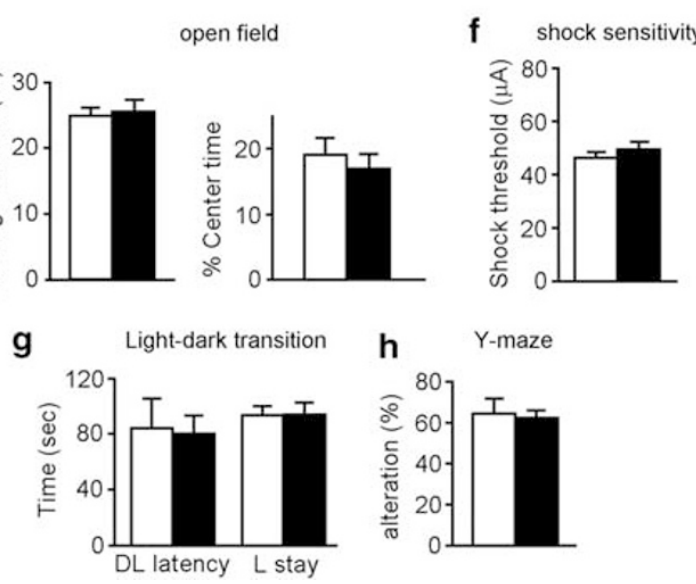

Figure 2 (a-d) Extinction of contextual fear memory. (a) Freezing rates during $10 \mathrm{~min}$ extinction training and test sessions (24 and $48 \mathrm{~h}$ after conditioning, $n=10$ per group). (b) Freezing rate of each animal in the test session of (a) was normalized to its freezing rate in extinction training. ( $c$ and d) Time course of the freezing rate during extinction training (c) and test $(d)$. (e-h) Mouse behavior in the open-field test $(e ; n=12)$, shocksensitivity test ( $f ; n=8)$, light-dark transition test ( $g ; n=8)$, and $Y$-maze test $(h ; n=10)$. All data are shown as means \pm SEM. $* P<0.05$, one-way analysis of variance (ANOVA) and post hoc Bonferroni comparison.

attenuating effect of the $5 \%$ krill diet, we administered the $\mu$-opioid antagonist NLX (3 mg/kg, subcutaneously). NLX failed to abolish the fear response attenuation in 5\% krill diet-fed mice when administered $60 \mathrm{~min}$ before the exposure test (comparison of 5\% krill $+\mathrm{VEH}$ and $5 \%$ krill + NLX; NLX had no effect on mice fed the control 1 diet; $\mathrm{F}(1,36)=18.25, P<0.001$ for diet, $\mathrm{F}(1,36)=0.49, P>0.05$ for drug, $F(1,36)=0.11, P>0.05$ for interaction with twoway ANOVA; $n=10$ for all four groups; Figure $3 \mathrm{c}$ ). Figure $3 \mathrm{~d}$ shows the time course of the freezing rate in Figure $3 \mathrm{c}$. These results indicate that the $\mathrm{CB}_{1}$ receptor, and not the $\mu$-opioid receptor, is involved in the effect of RIM on the behavior of mice fed the $5 \%$ krill diet.

\section{mRNA Levels}

We compared $\mathrm{CB}_{1}$ receptor mRNA levels in the brain (the remaining tissue after removal of the basal ganglia and hippocampus from the cerebrum) of mice fed the control 1 
a
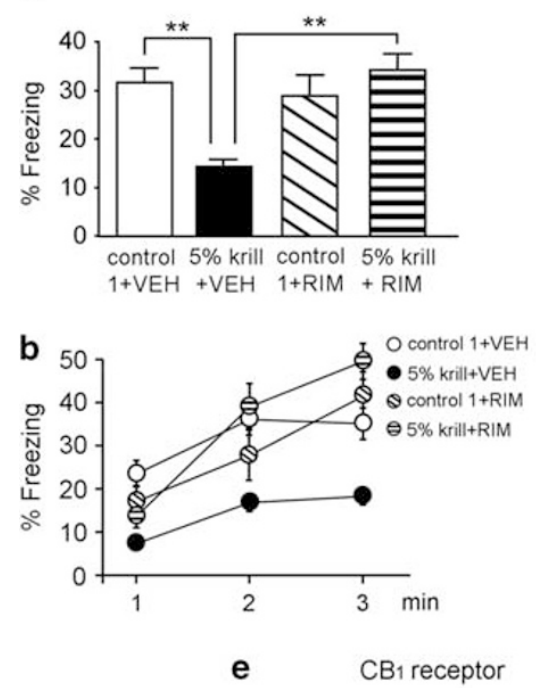

e $\quad$ CB1 receptor



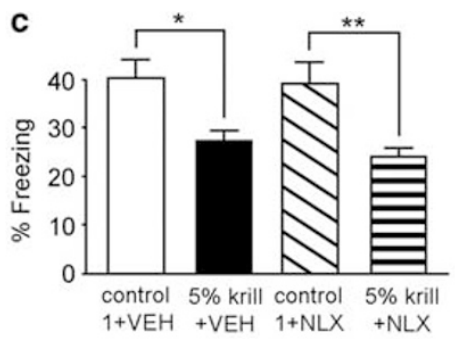
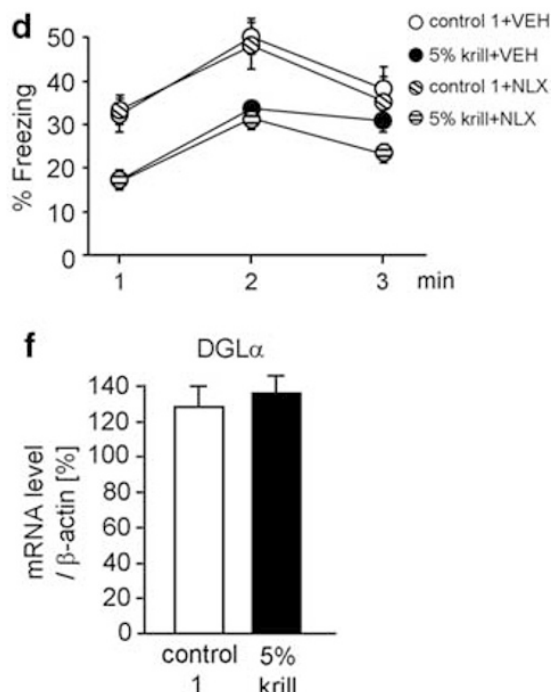

Figure 3 Involvement of type I cannabinoid $\left(C B_{1}\right)$ receptors in the fear-attenuating effect of the high 3:6 ratio diet. (a) Administration of the $C B_{1}$ receptor antagonist rimonabant (RIM, $3 \mathrm{mg} / \mathrm{kg}$ ) $60 \mathrm{~min}$ before the test abolished the effect of the $5 \% \mathrm{krill}$ diet on fear memory ( $n=10$ per group). (b) Time course of the freezing rate during the test session in (a). (c) Administration of the $\mu$-opioid receptor antagonist naloxone (NLX, $3 \mathrm{mg} / \mathrm{kg}$ ) $60 \mathrm{~min}$ before the test did not change the effect of the $5 \%$ krill diet on fear memory ( $n=10$ per group). (d) Time course of the freezing rate during the test session in (c). (e and f) Quantitative polymerase chain reaction (PCR) for CB, receptor (e) and diacylglycerol lipase $\alpha$ (DGL $\alpha$; $f$ ) analyses of brain extracts from mice fed the control I and $5 \%$ krill diets ( $n=6$ per group). $V E H$, vehicle. All data are shown as means $\pm S E M$. $P<0.05$, $* * P<0.01$, two-way analysis of variance (ANOVA) and post hoc Bonferroni comparison.

and $5 \%$ krill diets ( $n=6$ per group) using quantitative PCR (Figure 3e), but no difference in expression level was detected $(P>0.05$ with $t$-test $)$. We also analyzed mRNA levels of diacylglycerol lipase $\alpha$, a key enzyme in the biosynthesis of endocannabinoid 2-arachidonoylglycerol (Kano et al, 2009), but there was no significant difference in levels between the mice fed the control 1 and $5 \%$ krill diets $(P>0.05$ with $t$-test; $n=6$ per group; Figure 3f).

\section{Agonist Sensitivity of $\mathrm{CB}_{1}$ Receptors in the BLA}

Next, we examined the function of $\mathrm{CB}_{1}$ receptors in mice fed the $5 \%$ krill diet compared with that in control 1 diet-fed mice. First, to examine the enhancement of $\mathrm{CB}_{1}$ receptor activity, we compared the effect of the $\mathrm{CB}_{1}$ agonist WIN $(0.1,0.3,1.0,3.0$, and $10 \mu \mathrm{M})$ on the amplitude of evoked excitatory postsynaptic currents (eEPSCs) in BLA pyramidal neurons between mice fed 5\% krill and control 1 diets. It is known that the eEPSCs are inhibited by WIN (Yoshida et al, 2011). The importance of the BLA in contextual fear conditioning is well established (LeDoux, 2000). The doseresponse curve for WIN was shifted to the left in mice fed the $5 \%$ krill diet compared with those fed the control 1 diet (Figures $4 \mathrm{a}$ and $\mathrm{b}$ ), suggesting that $\mathrm{CB}_{1}$ receptor activity was enhanced in mice fed the $5 \%$ krill diet.

\section{$\mathrm{CB}_{1}$ Receptor Activity and Cholesterol Expulsion in the BLA}

To identify the mechanism underlying aforementioned enhancement of $\mathrm{CB}_{1}$ receptor activity, we applied MCD, a drug that excludes membrane cholesterol (Bari et al, 2005a; Maccarone et al, 2009). Treatment of slices with MCD $(5 \mathrm{mM})$ resulted in significantly greater suppression of eEPSC amplitude in control 1 diet-fed mice, but not in mice fed the 5\% krill diet (Figures $4 \mathrm{a}$ and b). These results suggest that cholesterol is involved in the mechanism of action of the $5 \%$ krill diet.

\section{Facilitation of Depolarization-Induced Suppression of Excitation}

In the $\mathrm{CNS}$, the $\mathrm{CB}_{1}$ receptor is involved in depolarizationinduced suppression of excitation (DSE) (Ohno-Shosaku et al, 2002). We examined DSE to confirm enhancement of $\mathrm{CB}_{1}$ receptor activity. For this purpose, we recorded eEPSCs from BLA pyramidal neurons in brain slices (12 cells from five mice fed the control 1 diet and 11 cells from five mice fed the $5 \%$ krill diet). The eEPSCs were more strongly suppressed after $10 \mathrm{~s}$ of depolarization in mice fed the $5 \%$ krill diet than in those fed the control 1 diet (Figure 4c; the lower graph shows the time course of DSE). The DSE in the 
a

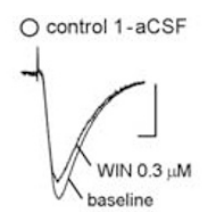

- $5 \%$ krill-aCSF

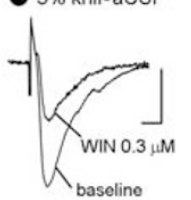

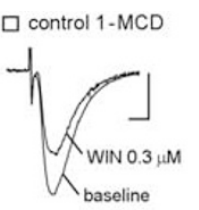

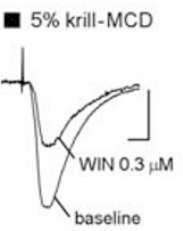

c
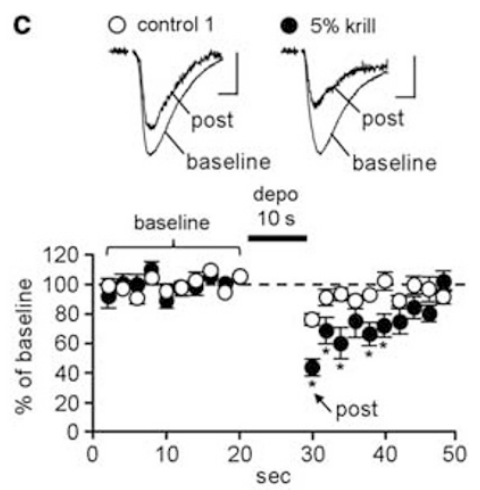

d



Figure 4 Electrophysiological analysis of type I cannabinoid $\left(C B_{1}\right)$ receptors. (a) Representative recordings in individual neurons before (baseline) and after the application of $0.3 \mu \mathrm{M}$ WIN55,2 I 2-2 (WIN). (b) Reduction of evoked excitatory postsynaptic current (eEPSC) amplitude by application of various concentrations of WIN $(0.1,0.3,1.0,3.0$, and $10 \mu \mathrm{M} ; n=4-6)$. Data were fitted using sigmoidal function (eight cells from seven mice for control-artificial cerebrospinal fluid (aCSF); 10 cells from seven mice for control-methyl- $\beta$-cyclodextrin (MCD); 10 cells from six mice for $5 \%$ krill-aCSF, and eight cells from six mice for $5 \%$ krill-MCD). Note that the dose-response curve for WIN was shifted to the left in mice fed 5\% krill diet ('5\% krill-aCSF', half-maximal effective concentration $\left(E C_{50}\right)=0.15 \pm 0.08 \mu \mathrm{M}$ ) compared with mice fed control I diet ('control I-aCSF', $E C_{50}=1.52 \pm 0.19 \mu \mathrm{M}$ ), and that MCD treatment resulted in a leftward shift of the curve in mice fed control I diet ('control I-MCD', EC $50=0.23 \pm 0.05 \mu \mathrm{M}$ ) but not in mice fed 5\% krill diet ('5\% krill-MCD', $E C_{50}=0.21 \pm 0.09 \mu \mathrm{M}$ ). (c) Lower graph, time course of depolarization-induced suppression of excitation (DSE) in the basolateral nucleus of the amygdala (BLA) of mice fed the control I and 5\% krill diets ( 12 cells from five mice fed the control I diet; I I cells from five mice fed the 5\% krill diet); above, traces show representative recordings in individual neurons. (d) Lower graph, rimonabant (RIM, $5 \mu \mathrm{M}$ ) abolishes the effect of the 5\% krill diet on DSE (seven cells from four mice fed the control I diet; six cells from three mice fed the 5\% krill diet); above, traces show representative recordings in individual neurons. Scale: 5 ms and $50 \mathrm{pA}$. $* P<0.05$, one-way analysis of variance (ANOVA) and post hoc Bonferroni comparison. ${ }^{\text {) }} P<0.05$ between control-aCSF and controlMCD, $P<0.00$ I between control-aCSF and $5 \%$ krill-aCSF; $\left.{ }^{2}\right) P<0.05$ between control-aCSF and control-MCD, $P<0.0$ l between control-aCSF and $5 \%$ krillaCSF with one-way ANOVA and post hoc Bonferroni comparison. All experiments in Figure 4 were carried out in the mice to which no behavioral experiments were conducted.

control 1 diet group was weaker than the DSE previously reported in the BLA (Yoshida et al, 2011). The DSE was abolished by preincubation of the slices (control $1, n=7$; $5 \%$ krill diet, $n=6)$ with RIM ( $5 \mu \mathrm{M}$; Figure $4 \mathrm{~d})$, indicating that the investigated DSE was almost completely dependent on $\mathrm{CB}_{1}$ receptors. These results suggest that $\mathrm{CB}_{1}$ receptormediated short-term synaptic plasticity is increased in the BLA of mice fed the $5 \%$ krill diet.

\section{DISCUSSION}

In the present study, we found that the ratio of $n-3$ to $n-6$ PUFA is a factor regulating contextual fear memory via cannabinoid $\mathrm{CB}_{1}$ receptors. Previous reports suggest characteristic concentration-dependent actions of WIN (intraperitoneal injection) upon extinction of contextual fear memory (Pamplona et al, 2006). WIN enhances extinction of contextual fear memory in a low concentration $(0.25 \mathrm{mg} / \mathrm{kg})$, but higher concentrations, for example,
$2.5 \mathrm{mg} / \mathrm{kg}$, show no facilitation of extinction (Pamplona et al, 2006). In a similar experiment by the same authors on the other hand, a high concentration of WIN applied before conditioning suppresses the expression of contextual fear memory itself (Pamplona and Takahashi, 2006). Thus, the selective behavioral effects of $5 \%$ krill diet upon contextual fear memory are similar to those previously reported for high concentrations of WIN: extinction remains unchanged but the expression of fear memory itself is suppressed. In our electrophysiological experiments, we confirmed higher sensitivity to a $\mathrm{CB}_{1}$ receptor agonist in BLA neurons of mice fed 5\% krill diet compared with controls. We therefore hypothesize that the effects of $5 \%$ krill diet on fear memory are propagated by this increased sensitivity of $\mathrm{CB}_{1}$ receptors.

Because the BLA has an essential role in contextual fear conditioning (LeDoux, 2000), this brain region can be regarded as one of the candidates mediating the effects of $5 \%$ krill diet. However, the possibility of a contribution of other regions such as the hippocampus, PAG (Resstel et al, 
2008), and vmPFC (Lisboa et al, 2010) to the observed effects should be examined in a future study. In addition, because this memory is essential for individuals' survival, it seems that a warning is necessary in excessive reduction of this memory. Furthermore, our analysis of basal anxiety was conducted by the light-dark transition test alone. In mice fed 5\% krill diet, it could be that basal anxiety levels may be changed in other behavioral tests, such as the elevated plusmaze test. Further experiments should be carried out to elucidate basal anxiety levels in mice fed 5\% krill diet.

The mechanism linking PUFAs to $\mathrm{CB}_{1}$ receptors may be explained by enhancement of $\mathrm{CB}_{1}$ receptor activity in the plasma membrane, in which PUFAs are incorporated as the acyl groups in phospholipids. It is known that uptake of DHA into phospholipids results in the exclusion of cholesterol from the rafts in the membrane (Stillwell et al, 2005; Stillwell and Wassall, 2003). Other studies have suggested that the $C_{1}$ receptor is distributed in lipid rafts in the plasma membrane of cultured human breast cancer cells (Sarnataro et al, 2005) and C6 glioma cells (Bari et al, 2008), and that the $\mathrm{CB}_{1}$ receptor has a cholesterol-binding domain that suppresses receptor activity upon binding of cholesterol (Oddi et al, 2011). Therefore, the exclusion of cholesterol by DHA from the raft would enhance $\mathrm{CB}_{1}$ receptor activity, as the suppressive effect exerted by cholesterol on the $\mathrm{CB}_{1}$ receptor is reduced or even abolished (Bari et al, 2005a, b). Our electrophysiological findings on WIN-sensitivity and MCD action are in agreement with these biophysical and biochemical findings, although we cannot yet rule out the possibility that high 3:6 ratio diets alter levels of endocannabinoids in brain regions relevant to fear memory.

On the basis of previous findings and our results, we propose that the following molecular mechanism underlies the effects of a high 3:6 ratio diet on fear memory: (i) ingestion of a high 3:6 ratio diet increases DHA in neuronal plasma membranes in the brain; (ii) this excludes cholesterol from rafts in the plasma membrane; and (iii) this, in turn, facilitates the activity of $\mathrm{CB}_{1}$ receptors and alters the synaptic plasticity that is important for fear memory retrieval.

The lower solubility of cholesterol in the DHA-rich membrane is considered to be due to expansion of the space between acyl groups in the membrane with high levels of unsaturation (Wassall and Stillwell, 2008). The expansion of this space would be more prominent in DHA (with six double bonds) than LA (two double bonds) or AA (four double bonds) (Shaikh et al, 2006). This could explain why LA suppresses the action of DHA when a high 3:6 ratio diet supplemented with LA is consumed (AA is a major n-6 PUFA in the brain and is synthesized from LA). However, this does not rule out the possibility that n-6 PUFA compensates for the loss of n-3 PUFA when $n-3$ is deficient.

To summarize, the primary aim of the present study was to evaluate whether dietary $3: 6$ ratio influences fear memory. Indeed, dietary 3:6 ratio influenced contextual fear memory in mice, and the effects were abolished by a $\mathrm{CB}_{1}$ receptor antagonist. Consistent with this observation, the activity of $\mathrm{CB}_{1}$ receptors, as measured by WINsensitivity, was enhanced in the BLA of mice fed a high 3:6 ratio diet. In these mice, DSE was also enhanced in the
BLA. We suggest that cholesterol is involved in one of the possible mechanisms underlying the observed enhancement of $\mathrm{CB}_{1}$ activity. Our findings provide biological evidence that PUFA influences fear memory in fear conditioning.

\section{FUNDING AND DISCLOSURE}

This work was supported by the following grants KAKENHI (grant number 23500474), Intramural Research Grant for Neurological and Psychiatric Disorders of the National Center of Neurology and Psychiatry (grant numbers 22-5, 24-2, and 25-1) (to MS), and Grant-in-Aid for Scientific Research on Innovative Areas, Foundation of synapse and neurocircuit pathology (to $\mathrm{KW}$ ). The authors have no conflict of interest to declare.

\section{ACKNOWLEDGEMENTS}

We thank Drs Takao Shimizu, Shuh Narumiya and Masanobu Kano for their helpful advice on our work. We also thank Drs Yoshihiro Kita and Suzumi Tokuoka for discussion. We thank Wakako Seki for her help in the lipid analysis.

\section{REFERENCES}

Bari M, Battista N, Fezza F, Finazzi-Agro A, Maccarrone M (2005a). Lipid rafts control signaling of type- 1 cannabinoid receptors in neuronal cells. J Biol Chem 280: 12212-12220.

Bari M, Oddi S, De Simone C, Spagnolo P, Gasperi V, Battista N et al (2008). Type-1 cannabinoid receptors colocalize with caveolin-1 in neuronal cells. Neuropharmacology 54: 45-50.

Bari M, Paradisi A, Pasquariello N, Maccarrone M (2005b). Cholesterol-dependent modulation of type 1 cannabinoid receptors in nerve cells. J Neurosci Res 81: 275-283.

Cuthbert BN, Lang PJ, Strauss C, Drobes D, Patrick CJ, Bradley MM (2003). The psychophysiology of anxiety disorder: fear memory imagery. Psychophysiology 40: 407-422.

Debiec J, LeDoux JE (2006). Noradrenergic signaling in the amygdala contributes to the reconsolidation of fear memory: treatment implications for PTSD. Ann N Y Acad Sci 1071: 521-524.

Green P, Hermesh H, Monselise A, Marom S, Presburger G, Weizman A (2006). Red cell membrane omega-3 fatty acids are decreased in nondepressed patients with social anxiety disorder. Eur Neuropsychopharmacol 16: 107-113.

Horrocks LA, Farooqui AA (2004). Docosahexaenoic acid in the diet: its importance in maintenance and restoration of neuronal membrane function. Prostaglandins Leukot Essent Fatty Acids 70: $361-372$.

Jacka FN, Pasco JA, Williams LJ, Meyer BJ, Digger R, Berk M (2013). Dietary intake of fish and PUFA, and clinical depressive and anxiety disorders in women. Br J Nutr 109: 2059-2066.

Kano M, Ohno-Shosaku T, Hashimotodani Y, Uchigashima M, Watanabe M (2009). Endocannabinoid-mediated control of synaptic transmission. Physiol Rev 89: 309-380.

Lafourcade M, Larrieu T, Mato S, Duffaud A, Sepers M, Matias I et al (2011). Nutritional omega-3 deficiency abolishes endocannabinoid-mediated neuronal functions. Nat Neurosci 14: 345-350.

Larrieu T, Madore C, Joffre C, Layé S (2012). Nutritional n-3 polyunsaturated fatty acids deficiency alters cannabinoid receptor signaling pathway in the brain and associated anxiety-like behavior in mice. J Physiol Biochem 68: 671-681.

LeDoux JE (2000). Emotion circuits in the brain. Annu Rev Neurosci 23: 155-184. 
Lepage G, Roy CC (1986). Direct transesterification of all classes of lipids in a one-step reaction. J Lipid Res 27: 114-120.

Lisboa SF, Reis DG, da Silva AL, Correa FMA, Guimaraes FS, Resstel LBM (2010). Cannabinoid CB1 receptors in the medial prefrontal cortex modulate the expression of contextual fear conditioning. Int J Neuropsychopharmacol 13: 1163-1173.

Maccarrone M, De Chiara V, Gasperi V, Viscomi MT, Rossi S, Oddi S et al (2009). Lipid rafts regulate 2-arachidonoylglycerol metabolism and physiological activity in the striatum. J Neurochem 109: 371-381.

Mackowiak M, Chocyk A, Dudys D, Wedzony K (2009). Activation of $\mathrm{CB} 1$ cannabinoid receptors impairs memory consolidation and hippocampal polysialylated neural cell adhesion molecule expression in contextual fear conditioning. Neuroscience 158: $1708-1716$

Marsicano G, Wotjak CT, Azad SC, Bisogno T, Rammes G, Cascio MG et al (2002). The endogenous cannabinoid system controls extinction of aversive memories. Nature 418: 530-534.

Matsuoka Y, Nishi D, Yonemoto N, Hamazaki K (2010). Omega-3 fatty acids for secondary prevention of posttraumatic stress disorder after accidental injury an open-label pilot study. J Clin Psychopharmacol 30: 217-219.

Milad MR, Rauch SL, Pitman RK, Quirk GJ (2006). Fear extinction in rats: implications for human brain imaging and anxiety disorders. Biol Psychol 73: 61-71.

Nishi D, Koido Y, Nakaya N, Sone T, Noguchi H, Hamazaki K et al (2012). Fish oil for attenuating posttraumatic stress symptoms among rescue workers after the great east Japan earthquake: a randomized controlled trial. Psychother Psychosom 81: 315-317.

Oddi S, Dainese E, Fezza F, Lanuti M, Barcaroli D, De Laurenzi V et al (2011). Functional characterization of putative cholesterol binding sequence (CRAC) in human type-1 cannabinoid receptor. J Neurochem 116: 858-865.

O'Donnell T, Hegadoren KM, Coupland NC (2004). Noradrenergic mechanisms in the pathophysiology of post-traumatic stress disorder. Neuropsychobiology 50: 273-283.

Ohno-Shosaku T, Tsubokawa H, Mizushima I, Yoneda N, Zimmer A, Kano M (2002). Presynaptic cannabinoid sensitivity is a major determinant of depolarization-induced retrograde suppression at hippocampal synapses. J Neurosci 22: 3864-3872.

Pamplona FA, Prediger RDS, Pandolfo P, Takahashi RN (2006). The cannabinoid receptor agonist WIN 55,212-2 facilitates the extinction of contextual fear memory and spatial memory in rats. Psychopharmacology 188: 641-649.

Pamplona FA, Takahashi RN (2006). WIN55,212-2 impairs contextual fear conditioning through the activation of CB1 cannabinoid receptors. Neurosci Lett 397: 88-92.

Rauch SL, Shin LM, Phelps EA (2006). Neurocircuitry models of posttraumatic stress disorder and extinction: human neuroimaging research-past, present, and future. Biol Psychiatry 60: 376-382.

Reeves PG, Nielsen FH, Fahey GC (1993). AIN-93 purified diets for laboratory rodents: final report of the American institute of nutrition ad hoc writing committee on the reformulation of the AIN-76A rodent diet. J Nutr 123: 1939-1951.

Resstel LBM, Lisboa SF, Aguiar DC, Correa FMA, Guimaraes FS (2008). Activation of CB1 cannabinoid receptors in the dorsolateral periaqueductal gray reduces the expression of contextual fear conditioning in rats. Psychopharmacology 198: 405-411.

Rinaldi-Carmona M, Barth F, Héaulme M, Shire D, Calandra B, Congy C et al (1994). SR141716A, a potent and selective antagonist of the brain cannabinoid receptor. FEBS Lett 350: 240-244.

Sakurai M, Sekiguchi M, Zushida K, Yamada K, Nagamine S, Kabuta $\mathrm{T}$ et al (2008). Reduction in memory in passive avoidance learning, exploratory behaviour and synaptic plasticity in mice with a spontaneous deletion in the ubiquitin C-terminal hydrolase L1 gene. Eur J Neurosci 27: 291-701.

Salem N Jr, Niebylski CD (1995). The nervous system has an absolute molecular species requirement for proper function. $\mathrm{Mol}$ Mem Biol 12: 131-134.

Sarnataro D, Grimaldi C, Pisanti S, Gazzerro P, Laezza C, Zurzolo $C$ et al (2005). Plasma membrane and lysosomal localization of $\mathrm{CB}_{1}$ cannabinoid receptor are dependent on lipid rafts and regulated by anandamide in human breast cancer cells. FEBS Lett 579: 6343-6349.

Sarter M, Bodewitz G, Stephens DN (1988). Attenuation of scopolamine-induced impairment of spontaneous alteration behaviour by antagonist but not inverse agonist and agonist beta-carbolines. Psychopharmacology (Berl) 94: 491-495.

Sink KS, Segovia KN, Collins LE, Markus EJ, Vemuri VK, Makriyannis A et al (2010). The CB1 inverse agonist AM251, but not the CB1 antagonist AM4113, enhances retention of contextual fear conditioning in rats. Pharmacol Biochem Behav 95: 479-484.

Stillwell W, Wassall SR (2003). Docosahexaenoic acid: membrane properties of a unique fatty acid. Chem Phys Lipids 126: 1-27.

Stillwell W, Shaikh SR, Zerouga M, Siddiqui R, Wassall SR (2005). Docosahexaenoic acid affects cell signaling by altering lipid rafts. Reprod Nutr Dev 45: 559-579.

Shaikh SR, Cherezov V, Caffrey M, Soni SP, LoCascio D, Stillwell $\mathrm{W}$ et al (2006). Molecular organization of cholesterol in unsaturated phosphatidylethanolamines: X-ray diffraction and solid state ${ }^{2} \mathrm{H}$ NMR reveal differences with phosphatidylcholines. J Am Chem Soc 128: 5375-5383.

Takeuchi T, Iwanaga M, Harada E (2003). Possible regulatory mechanism of DHA-induced anti-stress reaction in rats. Brain Res 964: 136-143.

Wassall SR, Stillwell W (2008). Docosahexaenoic acid domains: the ultimate non-raft membrane domain. Chem Phys Lipids 153: 57-63.

Yamada D, Zushida K, Wada K, Sekiguchi M (2009). Pharmacological discrimination of extinction and reconsolidation of contextual fear memory by a potentiator of AMPA receptors. Neuropsychopharmacology 34: 2574-2584.

Yamada D, Miyajima M, Ishibashi H, Wada K, Seki K, Sekiguchi M (2012). Adult-like action potential properties and abundant GABAergic synaptic responses in amygdala neurons from newborn marmosets. J Physiol 590: 5691-5706.

Yang X, Sheng W, Sun GY, Lee JC-M (2011). Effects of fatty acid unsaturation numbers on membrane fluidity and $\alpha$-secretasedependent amyloid precursor protein processing. Neurochem Int 58: 321-329.

Yoshida T, Uchigashima M, Yamasaki M, Katona I, Yamazaki M, Sakimura $\mathrm{K}$ et al (2011). Unique inhibitory synapse with particularly rich endocannabinoid signaling machinery on pyramidal neurons in basal amygdaloid nucleus. Proc Natl Acad Sci USA 108: 3059-3064.

Youdim KA, Martin A, Joseph JA (2000). Essential fatty acids and the brain: possible health implications. Int J Dev Neurosci 18: 383-399.

Zádor F, Otvos F, Benyth S, Zimmer Z, Paldy E (2012). Inhibition of forebrain mu-opioid receptor signaling by low concentrations of rimonabant does not require cannabinoid receptors and directly involves mu-opioid receptors. Neurochem Int 61: 378-388.

Zushida K, Sakurai M, Wada K, Sekiguchi M (2007). Facilitation of extinction learning for contextual fear memory by PEPA: a potentiator of AMPA receptors. J Neurosci 27: 158-166.

Supplementary Information accompanies the paper on the Neuropsychopharmacology website (http://www.nature.com/npp) 